\title{
Assessing clinical and psychological features: who are patients showing a nocebo reaction during the drug challenge test?
}

\author{
${ }^{1}$ Department of Educational Sciences, University of Genoa, Genoa, Italy \\ ${ }^{2}$ Allergy clinic, Casa della salute, Genoa, Italy \\ ${ }^{3}$ ASL 3 Genovese, Department of Mental Health and Addictions, Genoa, Italy
}

\section{KEY WORDS}

adverse drug reaction; nocebo effects; challenge test; psychological assessment; risk factors

\author{
Corresponding author \\ Fabiola Bizzi \\ Department of Educational Sciences \\ University of Genoa \\ C.A. Podestà 2, 16124 Genoa, Italy \\ Phone: +393381761203 \\ E-mail: fabiola.bizzi@edu.unige.it
}

\section{Doi}

10.23822/EurAnnACI.1764-1489.116

\begin{abstract}
Summary
The nocebo reaction, namely the undesirable effect of an inert substance (placebo), is a phenomenon rarely investigated in literature. A better knowledge of this reaction may help clinicians in the management of these patients in clinical practice. Patients with drug adverse reactions $(A D R)$ undergoing the drug challenge test are an ideal model for studying the nocebo effect, and the study aims to investigate their clinical and psychological features. One hundred and twenty patients ( $M_{\text {age }}=46.59, S D=15.5 ; 82 \%$ female), of which 90 non responders and 30 with nocebo reactions (25\%) were recruited, and completed a battery of psychological measures: State-Trait Anxiety Inventory X1-X2, Beck Depression Inventory II, Symptoms Checklist-90-R, Difficulties in Emotion Regulation Scale, Toronto Alexithymia Scale. Clinical features (individual characteristics and ADR clinical history) were collected by clinicians. The results show that older age $(p=0.002)$, low level of education $(p=0.039)$ and a depressive tendency $(p=0.030)$ appear to be potential risk factors for nocebo effects. Although none of the features related to the previous clinical history appear to represent a risk factor for the nocebo reactions ( $p>0.05)$, significant correlations between some of the clinical and psychological characteristics considered ( $p$ values from 0.005 to 0.042) help to better delineate the profile of these reactive patients. A specific training of the sanitary team about psychological aspects is recommendable.
\end{abstract}

\section{Introduction}

The term "nocebo" was originally used to differentiate the undesirable effects following the administration of an inert substance that the patient believes to be an active drug (during both pharmacological treatment and challenge test experimental studies). It is defined as the negative equivalent of the known placebo phenomenon. The nocebo reaction usually occurs in a subjective way with nonspecific symptoms (gastrointestinal symptoms, dizziness, headache, itching, paresthetic and thermal sensations), but sometimes also with objective signs (cutaneous, respiratory, gastric, cardiac rhythm or blood pressure changes). Like the placebo effect, the nocebo effect can have an important impact on the clinical practice and the outcome of clinical trials $(1,2,3,4,5)$.
Patients with adverse drug reactions (ADR) are an ideal model for studying the nocebo effect, because their previous experience can generate a negative expectation conditioning their acceptance and results of subsequent therapies. In many ADR cases, the allergy diagnostic workup includes the systemic challenge (oral or parenteral), to confirm the responsibility of a drug in the reaction and to identify alternative drugs that can be safely used (6). The experience of allergists is that some patients may show negative reactions to the administration of an inert substance (placebo) which usually precedes the active drug. The practice using placebo has the purpose to better evaluate the test results, evidencing a possible adverse reaction - the nocebo effect - that is reported by literature in percentages ranging from $3 \%$ to $27 \%(7,8,9)$. Lombardi and colleagues (8) stressed that the 
quality of medical-patient communication, and the empathetic approach by medical and nursing staff could be associated with a lower frequency of nocebo reactions.

Therefore, it is important to improve the clinical practice checking whether there are variables regarding the type of reactions experienced by patients, or particular psychological features enabling specialists to identify such subjects before submitting them to challenge tests (10). This may require specific training of specialists, but could be useful to increase the reliability of the allergy diagnostic workup.

The present study aims to investigate the clinical (individual characteristics and ADR clinical history) and psychological features (anxiety, depression, psychological symptoms, emotion dysregulation, and alexithymia) of patients with nocebo effect to oral challenge test compared with patients without reactions. At the exploratory level, the association between clinical and psychological features in nocebo patients are also investigated, to better delineate the profile of the reactive patients.

\section{Materials and methods}

Among all the patients with a clinical history of ADR, 120 were recruited consecutively from the Allergy Unit of the San Martino IST University Hospital (Genoa, Italy) in the first months of 2016, because they needed to be submitted to challenge test.
The allergist proposed and asked the patient consent to take part in the study. This study was conducted following the ethical standards established in the Declaration of Helsinki of 1946. Based on the clinical features of the ADR, the allergist decided the diagnostic workup in agreement with the patient, including the oral challenge test for one or more drugs. In the first day, after clinical evaluation of the patient including heart rate, blood pressure, and respiratory function, four doses of a placebo (water or talc) were administered at 30' intervals in a single-blind way. The patient was observed for one hour after the last dose and re-evaluated by the sanitary team before leaving the hospital. The day after, before the active drug administration, patients were required to report any symptoms at home. At the beginning of the test, a battery of psychological questionnaires was proposed by the psychologists to the patient, with the task of completing them by the first day.

Two groups of patients, negative $(\mathrm{n}=90)$ and positive $(\mathrm{n}=30)$ for nocebo effects occurring after administration of the "placebo" were selected and compared in this study. Socio-demographic features, associated pathologies and clinical characteristics of the $\mathrm{ADR}$ were analyzed (i.e. number of reactions, number and class of drugs involved, timing and severity of symptoms, emergency services access, history compatible with drug hypersensitivity diagnosis). The battery of psychological self-report administered (validated in Italian context) are summarized in table $\mathbf{I}$.

Table I - Battery of psychological questionnaire for psychological assessment.

\begin{tabular}{|c|c|c|c|}
\hline Measure & Questionnaire (authors) & Number of items & Subscales \\
\hline anxiety & $\begin{array}{l}\text { state-trait anxiety inventory } \\
\text { X1-X2 (CBA, 12) }\end{array}$ & $\begin{array}{l}20 \\
20\end{array}$ & $\begin{array}{l}\text { state anxiety (STAI-X1) } \\
\text { trait anxiety (STAI-X2) }\end{array}$ \\
\hline depression & $\begin{array}{l}\text { Beck depression inventory II } \\
\text { (BDI, 13) }\end{array}$ & 21 & total score \\
\hline $\begin{array}{l}\text { psychological } \\
\text { symptoms }\end{array}$ & $\begin{array}{l}\text { symptoms checklist-90-R } \\
\text { (SCL-90-R, 14) }\end{array}$ & 90 & $\begin{array}{l}\text { somatization (SOM) } \\
\text { obsessive-compulsive (O-C) } \\
\text { interpersonal sensitivity (I-S) } \\
\text { depression (DEP) } \\
\text { anxiety (ANX) } \\
\text { anger hostility (HOS) } \\
\text { phobic anxiety (PHOB) } \\
\text { paranoid ideation (PAR) } \\
\text { psychoticism (PSY) } \\
\text { global severity index (GSI) }\end{array}$ \\
\hline $\begin{array}{l}\text { emotional } \\
\text { regulation- } \\
\text { dysregulation }\end{array}$ & $\begin{array}{l}\text { difficulties in emotion } \\
\text { regulation scale (DERS, 15) }\end{array}$ & 36 & $\begin{array}{l}\text { non-acceptance of emotional response (Non-acceptance) } \\
\text { difficulties engaging in goal-directed behavior (Goal) } \\
\text { impulse control difficulties (Impulse) } \\
\text { lack of emotional awareness (Awareness) } \\
\text { limited access to emotion regulation strategies (Strategies) } \\
\text { lack of emotional clarity (Clarity) } \\
\text { total score (DERS Total) }\end{array}$ \\
\hline alexithymia & $\begin{array}{l}\text { Toronto alexithymia scale } \\
\text { (TAS-20,16) }\end{array}$ & 20 & $\begin{array}{l}\text { difficulty in identifying feelings (DIF) } \\
\text { difficulty in describing feelings (DDF) } \\
\text { external oriented thinking (POE) } \\
\text { total score (TAS-20 Total) }\end{array}$ \\
\hline
\end{tabular}


Clinical data collected by the clinicians in a data sheet were analyzed in aggregated form using the Statistical Package for Social Science (Version 23.0; IBM Corp., Armonk, NY, USA). Chi square test and independent-sample $t$ test were used to compare the clinical and psychological features of two groups. The multivariate analysis was used to control the effect of socio-demographic data differing two groups. Point biserial correlations were used to compare the association between nominal (clinical data) and quantitative variables (psychological measures). The level of significance for all analyses was $\mathrm{p}<0.05$.

\section{Results}

One hundred and twenty patients $\left(\mathrm{M}_{\text {age }}=46.59, \mathrm{SD}=15.5\right.$; $82 \%$ female) evaluated for an ADR clinical history completed the allergy and psychological tests. A nocebo effect was observed in thirty patients (25\%), of which 18 complained symptoms during or within one hour after the last dose of placebo administration and 12 reported reactions later, at home. Most of the symptoms were subjective, with a few cases of objective reactions: $27 \%$ skin symptoms (itching, burning sensation, paresthesia), $33 \%$ neurological symptoms (agitation, tremors, dizziness, headache), 20\% gastrointestinal symptoms (nausea, abdominal pain, diarrhea), 10\% respiratory symptoms (dyspnea, laryngeal obstruction sensation), 10\% cardiovascular symptoms (hypo or hypertension, tachycardia). Some patients complained more than one symptom, in four cases both in hospital than later, at home. In almost all cases the reactions were mild and patients immediately evaluated by the responsible allergist. Only one patient refused to continue the test, the day after, with active drug.

Comparing patients with nocebo reactions $(\mathrm{n}=30)$ with non responders $(n=90)$ respect to some socio-demographic data and associated pathologies (table II), significant differences on age (nocebo group: $\mathrm{M}_{\text {age }}=54.20, \mathrm{SD}=12.77$; non responders group: $\left.\mathrm{M}_{\text {age }}=44.06, \mathrm{SD}=15.56 ; \mathrm{t}_{(118)}=3.22, \mathrm{p}=0.002\right)$ and educational level (nocebo group: $33 \%$ had the junior high school license; non responders group: $16 \%$ had the junior high school license; $\mathrm{X}_{(2)}^{2}=6.47, \mathrm{p}=0.039$ ) were found. The two groups differed only marginally for gender (nocebo group: $93 \%$ female; non responders group: $78 \%$ female; $\mathrm{X}_{(1)}^{2}=3.64, \mathrm{p}=$ $0.057)$. No significant difference resulted for associated pathologies, including atopy.

Table III shows the clinical features (i.e. number of drug reactions, number of implicated drugs, timing of reactions, symptoms, severity of reactions, emergency services access, and compatible diagnosis of drug hypersensitivity) comparing patients with nocebo reactions with non responders. No significant difference was found ( $p>0.05)$.

In table IV are shown the results of psychological assessment (i.e. anxiety, depression, psychological symptoms, emotional regulation-dysregulation, and alexithymia), comparing patients with nocebo reactions with non responders. The only significant difference (even if minimal) between the two groups was found on SCL-90-R Depression $\left(\mathrm{t}_{(118)}=2.19, \mathrm{p}=0.030\right)$, showing higher level of depression symptoms in nocebo patients $(\mathrm{M}=2.00, \mathrm{SD}$ $=0.88)$ than in non responders $(\mathrm{M}=1.69, \mathrm{SD}=0.58)$.

Table II - Socio-demographic data and associated pathologies of patients.

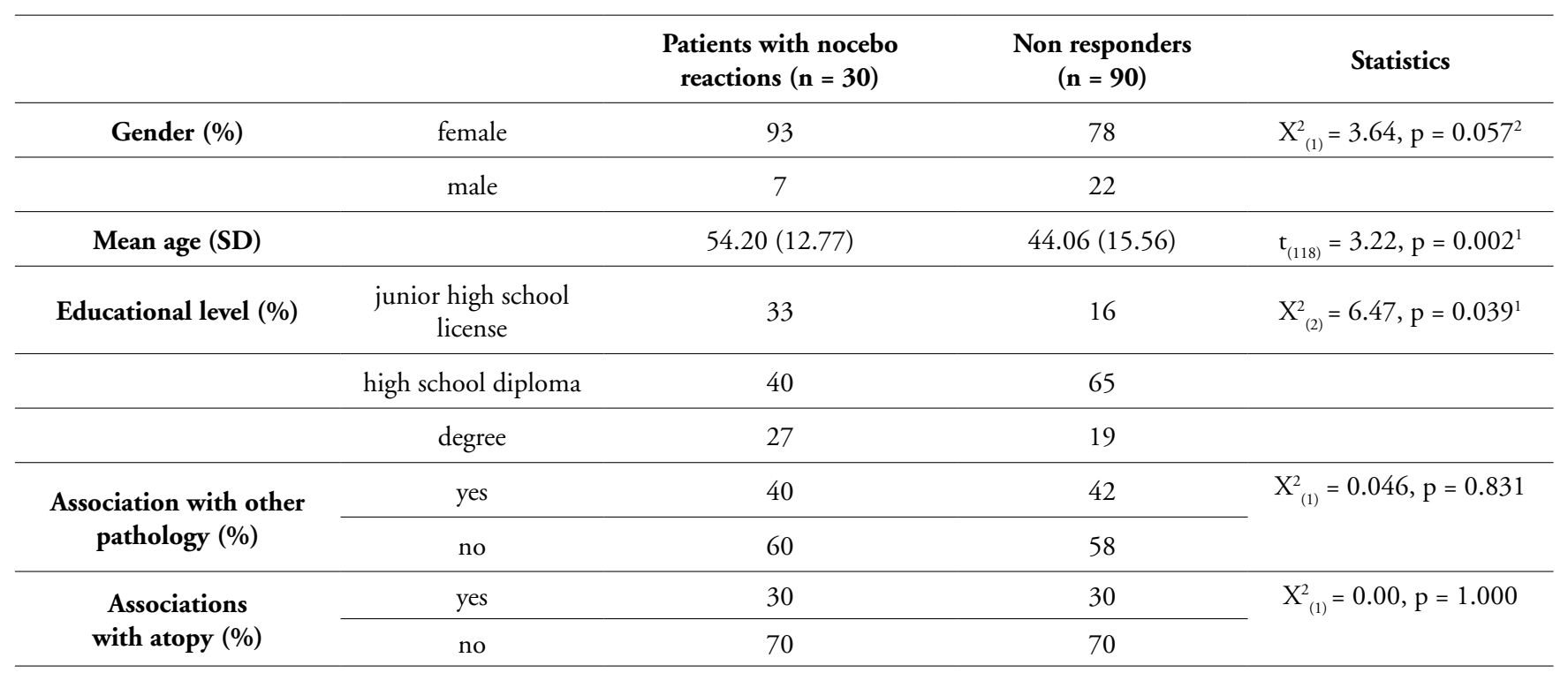

$\mathrm{p}<0.05^{1} ; \mathrm{p}<0.10^{2}$ 
Table III - Clinical features of ADR patients: the comparison between patients with nocebo effects and non responders.

\begin{tabular}{|c|c|c|c|c|}
\hline & & $\begin{array}{l}\text { Patients with nocebo } \\
\text { reactions }(\mathrm{n}=\mathbf{3 0})\end{array}$ & $\begin{array}{l}\text { Non responders } \\
\quad(\mathbf{n}=90)\end{array}$ & Statistics \\
\hline \multirow[t]{2}{*}{ Number of drug reactions (\%) } & 1 & 20 & 25.6 & $\begin{array}{c}\mathrm{X}_{(1)}^{2}=0.38, \mathrm{p}= \\
0.538\end{array}$ \\
\hline & $>1$ & 80 & 74.4 & \\
\hline \multirow[t]{2}{*}{ Number of implicated drugs (\%) } & 1 & 43.3 & 55.6 & $\begin{array}{c}\mathrm{X}_{(1)}^{2}=1.35, \mathrm{p}= \\
0.246\end{array}$ \\
\hline & $>1$ & 56.7 & 44.4 & \\
\hline \multirow[t]{3}{*}{ Timing of reactions (\%) } & immediate & 63.3 & 46.7 & $\begin{array}{c}\mathrm{X}_{(2)}^{2}=5.30, \mathrm{p}= \\
0.071\end{array}$ \\
\hline & not immediate & 13.3 & 35.6 & \\
\hline & both & 23.3 & 17.8 & \\
\hline \multirow[t]{2}{*}{ Symptoms (\%) } & mono-symptomatic & 80 & 62.9 & $\begin{array}{c}\mathrm{X}_{(1)}^{2}=2.97, \mathrm{p}= \\
0.085\end{array}$ \\
\hline & multi-symptomatic & 20 & 37.1 & \\
\hline \multirow[t]{3}{*}{ Severity of reactions $(\%)$} & mild & 37.9 & 29.9 & $\begin{array}{c}\mathrm{X}_{(2)}^{2}=0.65, \mathrm{p}= \\
0.722\end{array}$ \\
\hline & moderate & 48.3 & 54 & \\
\hline & severe & 13.8 & 16.1 & \\
\hline \multirow[t]{2}{*}{ Emergency services access (\%) } & yes & 50 & 51.7 & $\begin{array}{c}\mathrm{X}_{(1)}^{2}=0.02, \mathrm{p}= \\
0.873\end{array}$ \\
\hline & no & 50 & 48.3 & \\
\hline \multirow[t]{2}{*}{$\begin{array}{c}\text { Compatible drug hypersensitivity } \\
\text { diagnosis (\%) }\end{array}$} & probable & 86.2 & 85.4 & $\begin{array}{c}\mathrm{X}_{(1)}^{2}=0.01, \mathrm{p}= \\
0.914\end{array}$ \\
\hline & not probable & 13.8 & 14.6 & \\
\hline
\end{tabular}

Table IV - Values and differences in psychological data resulting from the specific questionnaires.

\begin{tabular}{ccccc}
\hline & Patients with nocebo & Non responders M (SD) & Statistics t (118) \\
reactions M (SD) & $46.21(33.27)$ & $40.83(28.58)$ & 0.86 \\
\hline CBA & State Anxiety & $37.52(28.36)$ & $37.55(26.60)$ & -0.01 \\
\hline Trait Anxiety & $11.60(10.30)$ & $7.96(7.83)$ & 2.03 \\
\hline SCL-90-R & Depression & $1.96(0.67)$ & $1.67(0.55)$ & 2.34 \\
\hline & SOM & $1.83(0.67)$ & $1.70(0.53)$ & 1.05 \\
\hline O-C & $1.68(0.69)$ & $1.54(0.54)$ & 1.14 \\
\hline I-S & $2.00(0.88)$ & $1.69(0.58)$ & $2.19^{1}$ \\
\hline DEP & $1.78(0.73)$ & $1.57(0.53)$ & 1.68 \\
\hline ANX & $1.67(0.65)$ & $1.48(0.50)$ & 0.68 \\
\hline HOS & $1.32(0.68)$ & $1.25(0.42)$ & 1.56 \\
\hline
\end{tabular}


Table IV (continued)

\begin{tabular}{|c|c|c|c|c|}
\hline & & $\begin{array}{l}\text { Patients with nocebo } \\
\text { reactions } M(S D)\end{array}$ & Non responders $M(S D)$ & Statistics t (118) \\
\hline & PSY & $1.40(0.54)$ & $1.29(0.33)$ & 1.31 \\
\hline \multirow[t]{6}{*}{ DERS } & Non-Acceptance & $12.27(5.13)$ & $12.49(4.99)$ & -0.21 \\
\hline & Goals & $13.10(3.27)$ & $13.29(3.60)$ & -0.25 \\
\hline & Awareness & $23.43(4.41)$ & $22.67(3.55)$ & 0.96 \\
\hline & Strategy & $16.87(5.22)$ & $15.81(4.01)$ & 1.15 \\
\hline & Clarity & $12.80(1.19)$ & $13.20(1.36)$ & -0.14 \\
\hline & Total & $89.90(15.29)$ & $89.07(13.03)$ & 0.29 \\
\hline \multirow[t]{2}{*}{ TAS-20 } & DIF & $13.00(5.46)$ & $13.29(5.23)$ & -0.26 \\
\hline & Total & $106.60(14.43)$ & $104.32(14.98)$ & 0.73 \\
\hline
\end{tabular}

${ }^{1} \mathrm{p}<0.05$

To control age and educational level differences on psychological subscales scores between patients with nocebo group and non responders, multivariate analysis was applied. Findings showed no significant effect for educational level and for group $\mathrm{F}<1$, but significant effect for age, $\mathrm{F}(1,119)=1.88, \mathrm{p}=0.018$, eta $^{2}=0.32$. Significant interaction between educational level and group was found, $\mathrm{F}(1,119)=0.51, \mathrm{p}=0.025$, eta $^{2}=0.28$. At the exploratory level, the association between clinical and psychological features on nocebo group was analyzed. Significant correlations are shown in table V. Emergency services access $(0=$ access, $1=$ non access $)$ are negatively correlated with trait anxiety of CBA $\left(r_{b}=-0.437, p=0.016\right)$, and with TAS total $\left(r_{b}=-0.447, p=0.013\right)$. The time of previous drug reactions $(0=$ immediate; $1=$ non immediate reactions $)$ is positively correlated with various subscales of DERS (Non-acceptance, Impulse, Strategy, DERS Total) and SCL-90-R subscales (SOM, O-C, DEP, HOS, GSI) with p values from 0.042 to 0.005 .

\section{Discussion}

This is one of the few studies focused on patients with nocebo reactions to the placebo administration during the pharmacological challenge. The result as frequency of patients with nocebo reactions $(25 \%)$ is in line with other studies $(7,9)$, and higher than that of $3 \%$ reported and attributed by Lombardi (8) to the absence of cases of severe reactions in his sample of patients.

As in other studies, the nocebo symptoms were subjective and of mild severity in almost all cases, such as not able to hinder the continuation of the test after clinical examination, but perceived as troublesome by patients. Notably, more than one-third of re- sponders experienced reactions after several hours at home, despite a history of previous immediate drug reactions. The remainder complained about immediate symptoms or within one hour from the last dose of placebo administered in the hospital. This is not comparable with other studies, but deserves attention because it could be a key factor for the responders and have relevant practical implications, as the need to instruct the patient about

Table $\boldsymbol{V}$ - Point biserial correlations between clinical and psychological data in nocebo patients.

\begin{tabular}{cccc}
\hline CBA & Trait Anxiety & $\begin{array}{c}\text { The time } \\
\text { of reactions }\end{array}$ & $\begin{array}{c}\text { Healthcare } \\
\text { service }\end{array}$ \\
\hline SCL-90-R & SOM & $0.452^{1}$ & $-0.437^{1}$ \\
\hline & O-C & $0.566^{2}$ & - \\
\hline & DEP & $0.506^{1}$ & - \\
\hline & HOS & $0.550^{2}$ & - \\
\hline & GSI & $0.487^{1}$ & - \\
\hline DERS & Non- & $0.467^{1}$ & - \\
& acceptance & & - \\
\hline & Impulse & $0.507^{1}$ & - \\
\hline & Strategy & $0.428^{1}$ & - \\
\hline TAS-20 & Total & $0.470^{1}$ & - \\
\hline Total & - & $-0.447^{1}$ \\
\hline
\end{tabular}

${ }^{1} \mathrm{p}<0.05 ;{ }^{2} \mathrm{p}<0.01$ 
their possible appearance and their management. In any case, interpretation and discussion of the reactions with the patient may represent a problem for the clinicians and nurses involved.

The analysis of the socio-demographic data shows a prevalence of the female gender in line with the literature (7) in the nocebo group compared to non responders. Age and level of education are variables not previously reported as influential, while in our study higher age and lower level of education characterize the responders.

Considering that patient's expectation and previous experiences of untoward reactions to drugs are the main factors influencing the nocebo effect $(2,3)$, some of the clinical features of the previous drug reactions can be assumed as risk-factors. In our study, although $80 \%$ of responders reported more than one ADR, predominantly immediate (over 60\%), with compatible symptoms of hypersensitivity to drugs, and of moderate-severe degree (in $62 \%$ of cases), no significant difference has been demonstrated between the two groups.

According to the aim of this work to outline the profile of responders, various psychological variables were also analyzed (i.e. anxiety, depression, psychological symptoms, emotional regulation-dysregulation, and alexithymia). The only factors associated in the literature to the nocebo phenomenon are somatization tendency, anxiety and depression $(8,11)$, the latter suggested as a general feature of the ADR population (10). In our study, the only datum that seems to delineate the psychological profile of responders (controlling the effects of age and educational level) is the presence of depressive symptoms that confirm the data of the literature, while anxiety and somatization tendency, are not confirmed. These findings could reinforce the key-role that other factors, as negative expectation and pavlovian conditioning process with the consequent involvement of neurobiological mediators, play in nocebo reactions, as evidenced by studies of Benedetti (17) and Colloca (3). A more detailed analysis of the individual variables, however, shows that higher levels of trait anxiety and alexithymia appears to be associated with more frequent access to emergency services. In other words, this datum suggests that anxiety and alexithymia are individual features

\section{References}

1. Flaten MA, Simonsen T, Olsen H. Drug-related information generates placebo and nocebo responses that modify the drug response. Psychosom med 1999; 61(2):250-255.

2. Barsky AJ, Saintfort R, Rogers MP, Borus JF. Nonspecific medication side effects and the nocebo phenomenon. Jama 2002; 287(5):622-627.

3. Colloca L, Miller FG. The nocebo effect and its relevance for clinical practice. Psychosom Med 2011; 73(7):598-603.

4. Planès S, Villier C, Mallaret M. The nocebo effect of drugs. Pharmacol Res Perspect 2016; 4(2):e00208.

5. Häuser W, Hansen E. Enck P. Nocebo phenomena in medicine: their relevance in everyday clinical practice. Dtsch Ärztebl Int 2012; 109(26):459-465. making the nocebo patients more vulnerable to call for help. Besides, psychological symptoms and emotional dysregulation appear to be associated with the late-onset drug reactions. This could be interpreted with the greater vulnerability of nocebo patients to psychological discomfort, and with the greater difficulty of these patients to acceptance, evaluation and dealing with the drug reactions.

\section{Conclusions}

Despite the limitations of the study, such as the low sample size and the use of self-report measures, the findings seem to be clinically relevant. Female sex, older age and low level of education combined with a depressive tendency appear to be potential risk factors for nocebo effects appearing during oral challenge test in one among four patients. However, none of the features related to the previous clinical history of ADR appear to be associated with the possibility of nocebo reactions. Although various psychological features do not seem to outline a typical profile of responders, some of these patients show psychological symptoms and emotional problems significantly associated with the time of previous drug reactions and with the use of emergency services. In view of this, the training of the sanitary team dedicated to pharmacological challenges must include the psychological aspects (18). The verbal communication between health caregivers and patient, the patient education with respect to possible reactions, the understanding of what the patient needs to know about adverse effects, and the general clinical context are key factors for a proper assessment of this diagnosis, burdened with time and human resources high costs $(5,11)$.

\section{Aknowledgements}

We thanks the doctors S. Ravazza, A. Rametti, and D. Scopece for their help with data collection.

\section{Conflict of interest}

The authors declare that they have no conflict of interest.

6. Aberer W, Bircher A, Romano A, Blanca M, Campi P, Fernandez J, et al. Drug provocation testing in the diagnosis of drug hypersensitivity reactions: general considerations. Allergy 2003; 58(9):854863.

7. Liccardi G, Senna G, Russo M, Bonadonna P, Crivellaro M, Dama A et al. Evaluation of the nocebo effect during oral challenge in patients with adverse drug reactions. J Investig Allergol Clin Immunol 2004; 14(2):104-107.

8. Lombardi C, Gargioni S, Canonica GW, Passalacqua G. The nocebo effect during oral challenge in subjects with adverse drug reactions. Eur Ann Allergy Clin Immunol 2008; 40(4):138-141.

9. Passalacqua G, Milanese M, Mincarini M, Ciprandi G, Guerra L, Scordamaglia A, Canonica GW. Single-dose oral tolerance 
test with alternative compounds for the management of adverse reactions to drugs. Int Arch Allergy Immunol 2002; 129:242247.

10. Berrino AM, Voltolini S, Bignardi D, Fasce C, Minale P, Macchi M, Troise C. Psychological aspects of drug intolerance. Eur Ann Allergy Clin Immunol 2005; 37(3):90-95.

11. Hermes B, Hein, UR, Henz BM. Assessment of psychological aspects during systemic provocation tests in patients with pseudoallergic drug reactions. J Eur Acad Dermatol Venereol 2006; 20(7):800-803.

12. Sanavio E, Bertolotti G, Michielin P, Vidotto G, Zotti AM. CBA2.0 Cognitive Behavioural Assessment 2.0, Scale Primarie. Organizzazioni Speciali, Firenze, 1997.

13. Ghisi M, Flebus GB., Montano A, Sanavio E, Sica C. Beck depression inventory-II. Italian edition. Giunti Editore, Firenze, 2006.
14. Prunas A, Sarno I, Preti E, Madeddu F, Perugini M. Psychometric properties of the Italian version of the SCL-90-R: a study on a large community sample. Eur Psychiatry 2002; 27(8):591-597.

15. Giromini L, Velotti P, de Campora G, Bonalume L, Zavattini GC. Cultural adaptation of the difficulties in emotion regulation scale: Reliability and validity of an Italian version. J Clin Psychol 2012; 68(9):989-1007.

16. Bressi C, Taylor G, Parker J, Bressi S, Brambilla V, Aguglia E, et al. Cross-validation of the factor structure of the 20-item Toronto Alexithymia Scale: an Italian multicenter study. J Psychosom Res 1996; 41(6):551-559.

17. Enck P, Benedetti F, Schedlowski. New insights into the placebo and nocebo responses. Neuron 2008; 59(2):95-206.

18. Bizzi F, Sciarretta L, D'alessandro M, Picco P. A long-term psychological observation in an adolescent affected with Gardner diamond syndrome. Indian J Psychol Med, 2016; 38(1)74-77. 